\title{
Justice judgements, school failure, and adolescent deviant behaviour
}

\author{
Cristina Sanches ${ }^{1 *}$, Maria Gouveia-Pereira' and Felice Carugati ${ }^{2}$ \\ 'Research Unit on Cognitive, Developmental and Educational Psychology, ISPA \\ University, Portugal \\ ${ }^{2}$ Department of Education, Alma Mater Studiorum University of Bologna, Italy
}

Background. The current paper is based on two different approaches. One is the relational model of authority (Tyler \& Lind, 1992), which addresses the effects of justice perceptions on the legitimacy of authorities and behavioural compliance. The other is Emler and Reicher's theory $(1995,2005)$, which explains the involvement of adolescents in delinquency through their relationship with the institutional authorities of society.

Aims. To provide empirical evidence for the linkage of these perspectives, analysing the relationship between justice perceptions about teachers and the involvement of adolescents in deviant behaviour. Our hypotheses are that teachers' justice is negatively related with deviant behaviour and that this relationship is mediated through the evaluation of institutional authorities, after controlling for school failure.

Sample. Three hundred and ninety adolescents aged between 14 and 17 years.

Methods. Participants completed the following scales: perceptions of justice about teachers, evaluation of institutional authorities, and deviant behaviour. Data were examined through correlation and bootstrap analyses.

Results. Justice judgments about teachers were negatively related with deviant behaviour, and this relationship was partially mediated by the evaluation of institutional authorities, even after controlling for school failure. However, procedural justice revealed a much stronger relationship with deviance, compared to distributive justice.

Conclusions. As predicted, these results suggest that when adolescents perceive school authorities as fair, other institutional authorities are likely to be perceived in a similar way and the more those authorities are positively evaluated, the less often adolescents engage in deviant conduct. Results are discussed according to the theories underlying our hypothesis. Directions for future research are suggested.

Involvement in delinquent behaviour is explained by Emler and Reicher $(1995,2005)$ through the type of relationship that adolescents develop with the formal authorities of society. On the other hand, research within the field of social justice, namely the one

\footnotetext{
*Correspondence should be addressed to Cristina Sanches, Rua Jardim do Tabaco, 34, II49-04I Lisboa, Portugal (e-mail: csanches@ispa.pt).
} 
based on the relational model of authority (RMA) (Tyler \& Lind, 1992), demonstrates that authorities are considered legitimate and their decisions accepted and voluntarily obeyed to the extent that they use fair procedures and treat people with respect. The research presented in the current paper is based on these two perspectives and attempts to establish a link between them. To our knowledge, this link has not been empirically explored, specifically in the school setting. We will, therefore, analyse the relationship between the justice and injustice situations experienced with school authorities and youth involvement in deviant behaviour. With the term deviant behaviour, we refer to behaviour that violates legal norms (commonly designated as delinquent behaviour), but also behaviour that violates social norms, even if it is not punishable by law.

\section{The relationship between deviant behaviour, institutional authority and school}

From the perspective of Emler and Reicher (1995; 2005), delinquency is the behavioural manifestation of a 'breach' in the relationship between young people and institutional authority. It expresses the idea that adolescents are unwilling to accept and comply with the rules and norms of the social system, and of the authorities that represent it. This occurs because authorities are seen as not offering effective protection of people's rights or against victimisation. In this sense, the authors suggest that adolescent involvement in delinquency is linked to and sustained by a sense of exclusion from authorities. Empirical evidence gives support to some of these ideas by showing that the negative attitudes of adolescents towards institutional authorities (namely, the police and the law) are strongly correlated with non-compliance with rules and with involvement in delinquent acts (e.g., Emler \& Reicher, 1987, 1995; Hirschi, 1969; Hoge, Andrews, \& Leschied, 1996; Levy, 2001; Loeber, 1996; Reicher \& Emler, 1985; Tarry \& Emler, 2007).

According to Emler and Reicher $(1995,2005)$, besides intellectual growth, the development of attitudes and beliefs towards authorities is also determined by the experience of formal education. It is in the school setting that most children have their first direct and extended experience with institutional authority. It seems, therefore, likely that children develop a preliminary understanding of formal authority in the school setting, and that attitudes formed here are then generalized to other kinds of institutional authority (such as, the police or the law) with which they have less contact (Emler \& Reicher, 1995, 2005). Research has shown that between the ages of 6 and 10 children's understanding of the nature of formal authority in the school setting is far more developed than their understanding of other institutional authorities (Emler, 1992; Emler, Ohana, \& Moscovici, 1987). Empirical evidence has also consistently shown a strong positive relationship between the attitudes of adolescents towards school authorities and those towards other institutional authorities (Emler \& Reicher, 1987, 1995; Reicher \& Emler, 1985; Rigby \& Rump, 1979, 1981).

There are other school-related variables, which have also been associated with the attitudes of adolescents towards institutional authorities, namely school performance, the value assigned to school, adaptation to school rules, and school well-being (GouveiaPereira \& Pires, 1999; Palmonari \& Rubini, 1998; Palmonari, Rubini, \& Casoni, 1999). Further, recent studies have shown that teachers' negative perceptions about students, as well as students' negative assessments of the classroom environment, influence the attitudes of adolescents towards school authorities, and their aggressive behaviour in the school context (Estévez, Musitu, \& Herrero, 2005; López, Pérez, Ochoa, \& Ruiz, 2008; Murray \& Murray, 2004; Ochoa, López, \& Emler, 2007). Despite the results of these studies, we consider that the relationship between school experiences, namely 
the quality of interactions with teachers, and the involvement of adolescents in deviant conduct should be further explored and clarified. What is specifically happening within the context of student-teacher interactions that might contribute to the development of negative representations of institutional authorities and to the defiant and law-breaking behaviour of adolescents? We think that theory and empirical evidence based on the relationship between procedural justice (PJ) and the legitimacy of authorities might provide an important contribution in this direction.

\section{Justice judgements and the relationship with authorities}

Social psychologists have long analysed the role that the experiences of justice and injustice play in the life of individuals (e.g., Brockner \& Wiesenfeld, 1996; Lind \& Tyler, 1988; Tyler \& Blader, 2000; Tyler \& Lind, 1992; Van den Bos \& Lind, 2001). One of the most appealing findings in this field is the effect of justice judgments on authorities' legitimacy (Gouveia-Pereira, 2008; Sunshine \& Tyler, 2003; Tyler, 1990, 1997; Tyler \& Huo, 2002; Tyler \& Wakslak, 2004).

The RMA proposed by Tyler and Lind (1992), which is based on the group-value model (Lind \& Tyler, 1988), argues that authorities are considered legitimate to the extent that they use fair procedures and treat people with respect. And when authorities are considered legitimate, people are more likely to accept their decisions and voluntarily comply with rules, even when it is not to their immediate benefit. They do so because they prefer to maintain, in the long term, a positive relationship with the group to which they belong and with the authorities of that group. According to these models, fair treatment by authority figures matters to people because it provides information about their value and their social status in the group, thereby contributing to the definition of their identity (Tyler \& Blader, 2003). This idea follows the presuppositions of social identity theory (Tajfel \& Turner, 1986) and of self-categorisation theory (Turner, Hogg, Oakes, Reicher, \& Wetherell, 1987), according to which individuals use the information they acquire from the groups they belong to so as to construct their social identity.

Previous instrumental models of justice, such as those proposed by Adams (1965) or Berkowitz and Walster (1976), argued that when people make justice judgements, they are mainly concerned about distributive and instrumental aspects, such as the favourability of outcomes and the equitable distribution of resources. Instead, RMA argues that when making justice judgments about authorities, people are mainly concerned about relational and procedural aspects. Therefore, authorities will be considered fair and, subsequently, legitimate to the extent that people perceive that their decisions are oriented by the following relational principles: neutrality (e.g., the authority behaves the same for all individuals and uses neutral and impartial procedures in decision making), trust (e.g., the authority is honest and shows concern about people's needs and rights), and status recognition (e.g., the authority treats people with respect and dignity). The legitimacy of authorities in turn will contribute to people's voluntary acceptance and compliance with decisions and rules. These hypotheses have received empirical support in different contexts and cultures (e.g., Lind, Tyler, \& Huo, 1997; Sousa \& Vala, 2002; Sunshine \& Tyler, 2003; Tyler, 1990, 1997; Tyler \& Caine, 1981; Tyler \& Huo, 2002; Tyler, Degoey, \& Smith, 1996; Tyler \& Wakslak, 2004). However, these studies have been conducted with adults and not in the school setting.

An exception to this was the study developed by Gouveia-Pereira, Vala, Palmonari, and Rubini (2003) with 448 Portuguese adolescents, in order to understand better the process that underlies the relationship of adolescents with authorities at school and 
outside school. They found that justice judgments about teachers, especially procedural and relational judgments, were a critical factor in the legitimacy of school authority, as well as in the evaluation of institutional authorities (EIA) (such as police, courts, and laws). Moreover, the legitimacy of school authorities was a significant mediator in the relationship between justice judgments about teachers and the EIA outside school. The authors suggested that when adolescents perceive their teachers as being fair in procedural and relational domains, that perception is generalized to other authorities and formal institutions of society, in the sense that justice perceptions regarding the school authority (teacher) promote the internalization of positive representations about other authorities outside school.

Based on the results obtained by Gouveia-Pereira et al. (2003), and linking them to the research previously mentioned associating the attitudes towards institutional authorities and deviant behaviour, we wondered if justice perceptions about teachers would not also be related with adolescent involvement in deviant conducts, precisely through their association with the EIA. As far as we know, there has been no empirical research analysing these relationships and that is our main goal. Following this, we formulated two hypotheses. Our first hypothesis is that positive judgments about teacher fairness are negatively associated with adolescent deviant behaviour. Our second hypothesis is that the relationship between justice perceptions about teachers and deviant behaviour is mediated by adolescent evaluation of other institutional authorities of society, such as police officers, laws, judges, and courts. Our expectation is that the more adolescents perceive their teachers as fair, the more positive is their EIA and, in turn, the more positive that evaluation is, the less adolescents will be involved in deviant conduct. Also following the RMA and the empirical evidence, which supports its hypothesis, we expect these associations to be stronger for judgements about PJ rather than judgments about distributive justice (DJ). Moreover, empirical evidence has shown that school failure is strongly correlated with delinquency (e.g., Hargreaves, 1967; Kelly, 1975; Reiss \& Rhodes, 1961; West \& Farrington, 1977) and with adolescent psychosocial adaptation (Blankemeyer, Flannery, \& Vazsonyi, 2002; Reinke \& Herman, 2002). Therefore, school failure will be included as a control variable so as to ensure that it does not constitute a third cause explaining the mediation effects hypothesized.

\section{Method}

\section{Participants}

The participants of this study were 390 Portuguese adolescents aged between 14 and 17 years $(M=15.5 ; S D=1.11), 52 \%$ of who were boys and $48 \%$ girls. Data were collected in six schools in the urban area of Lisbon: four regular schools and two vocational schools. $59 \%$ of the participants were attending regular schools and were in ninth to 12th year. The remaining $41 \%$ were attending vocational schools and were in seventh to ninth year. Participant distribution according to age, gender, and number of school years failed is presented in Table 1 .

\section{Measures}

Perceptions of justice about teachers were measured using a 16-item scale developed by Gouveia-Pereira et al. (2003), based on Leventhal (1980) and Tyler et al. (1996). The scale included items of distributive justice (e.g., 'overall, teachers reward my efforts'), 
Table I. Frequencies of participants' age, gender, and number of school years failed

\begin{tabular}{|c|c|c|c|c|}
\hline \multirow[b]{2}{*}{ AGE } & \multirow{2}{*}{$\begin{array}{c}\text { Number of school } \\
\text { years failed }\end{array}$} & \multirow[b]{2}{*}{ Male } & GENDER & \multirow[b]{2}{*}{ Sub-total } \\
\hline & & & Female & \\
\hline \multirow[t]{3}{*}{14} & 0 (never) & 23 & 27 & 50 \\
\hline & I or more times & 26 & 16 & 42 \\
\hline & Sub-total & 49 & 43 & 92 \\
\hline \multirow[t]{3}{*}{15} & 0 (never) & 24 & 22 & 46 \\
\hline & I or more times & 29 & 21 & 50 \\
\hline & Sub-total & 53 & 43 & 96 \\
\hline \multirow[t]{3}{*}{16} & 0 (never) & 16 & 25 & 41 \\
\hline & I or more times & 36 & 26 & 62 \\
\hline & Sub-total & 52 & 51 & 103 \\
\hline \multirow[t]{3}{*}{17} & 0 (never) & 10 & 23 & 33 \\
\hline & I or more times & 38 & 28 & 66 \\
\hline & Sub-total & 48 & 51 & 99 \\
\hline
\end{tabular}

procedural justice (e.g., 'my teachers give me the chance to put forward my own points of view before making a decision about me'), and relational justice (e.g., 'my teachers treat me with respect and consideration') Responses were given on a five-point scale (1 = strongly disagree; 5 = strongly agree $)$.

A principal components analysis (PCA) was performed using varimax rotation for components extraction. Two components with an eigenvalue $>1$ emerged, explaining $51 \%$ of the total variance (Kaiser-Meyer-Olkin $(\mathrm{KMO})$ statistics $=.90$ ). The first component, with an eigenvalue of 6.6 , explained $41 \%$ of the variance and was loaded by PJ items together with relational justice items, with factor loadings ranging from .71 to .54 . The second component, with an eigenvalue of 1.5 , explained $10 \%$ of the variance, and was loaded by the DJ items, with factor loadings ranging from .87 to .53 . Procedural and relational justice items have also loaded together into the same component in the study of Gouveia-Pereira et al. (2003) as well as in previous studies (e.g., Folger, 1996; Sousa \& Vala, 2002; Vermunt, Van der Kloot, \& Van der Meer, 1993). Indeed, the more recent body of literature considers PJ a two-dimensional concept, consisting of quality of decision making and quality of treatment (e.g., Tyler \& Huo, 2002; Tyler \& Smith, 1997). Following this and based on the results of the PCA, two variables were therefore created: procedural justice, which was computed by making an average of all the items that loaded on the first component $(\alpha=.89 ; M=3.41 ; S D=.71)$; and distributive justice, which was computed by making an average of all the items that loaded on the second component $(\alpha=.82 ; M=3.56 ; S D=.79)$. A higher score on this scale indicated a more positive perception of teachers' justice.

The evaluation of institutional authorities was measured with a 19-item scale developed by Gouveia-Pereira et al. (2003), based on Reicher and Emler (1985) and Tyler (1990, 1997). This scale includes items that measure the evaluation of three types of institutional authority: police (e.g., 'sometimes the police arrest people unfairly'), laws (e.g., 'laws protect the rights of all citizens'), and judges/courts (e.g., 'the courts are there in order to make society better for everyone'). Responses were given on a fivepoint scale $(1=$ strongly disagree; $5=$ strongly agree $)$. Previous research has shown that adolescent evaluations concerning these authorities were positively inter-correlated 
and, therefore, these measures have been aggregated into a single variable (GouveiaPereira et al., 2003; Reicher \& Emler, 1985; Rigby, Schofield, \& Slee, 1987). Following this, participants' answers on this scale were averaged to compute a single variable: the evaluation of institutional authorities $(\alpha=.79 ; M=3.03 ; S D=.49)$. A higher score on this scale reflected a more positive EIA.

Adolescent deviant behaviour was measured with a 41-item scale developed by Gouveia-Pereira and Carita (2005). This scale measures the frequency of deviant behaviour that may have occurred in the past 2 years in different contexts: at school, at home, or in public places. The development of items was based on review of the literature (e.g., Hirschi, 1969; Smith \& Mc Vie, 2003; Vazsonyi, Pickering, Junger, \& Hessin, 2001) and semi-directive interviews with adolescents, to understand better what type of deviant behaviours were named by adolescent groups. Overall, items referred to: vandalism (e.g., 'I have damaged or destroyed public or private property (e.g. a phonebox, parking meters, street signs, cigarette vending machines, slashed tyres on cars or motorbikes, broken mirrors or windows')), addictive behaviour (e.g., 'I have smoked hashish or marijuana'), verbal and physical aggression (e.g., 'I have hit or thrown objects at a teacher or other adult at school'), lies (e.g., 'I have lied about my age to get into certain places such as a bar, a night club or the cinema'), school misconduct (e.g., 'I have skipped school because I did not feel like going and wanted to stay with friends, or to go for a walk'), thefts (e.g., 'I have stolen, or tried to steal, money or objects such as a cell phone, watch, MP3, etc., from a stranger'), use of weapons (e.g., 'I have used some kind of weapon (e.g. knife, etc.) when I was fighting with someone'), disobeying laws (e.g., 'I have driven a car or a motorcycle without having a drivers' licence'), and disobeying authority figures (e.g., 'I have gone out at night without my parents' permission'). Responses were given on a six-point scale $(0=$ never; $5=$ many times $)$.

A PCA with varimax rotation was carried out. A nine-components solution with an eigenvalue $>1$ emerged, explaining $67 \%$ of the total variance $(\mathrm{KMO}=.91)$. The screen plot showed, however, that the first component, with an eigenvalue of 13.82, was substantially stronger than all the other components, with eigenvalues ranging from 3.27 (in the second component) to 1.02 (in the ninth component). The first component alone explained more of the variance of the scale (37\%), than the other eight components together (30\%). Furthermore, since this solution was not easily interpretable, we performed a new PCA, but this time forcing the solution to a single component structure. Factor loadings for this solution (KMO = .91) ranged from .43 to .74 , indicating that all items were related to a single latent variable, although in different proportions. Based on these results, all the items of the scale were averaged to compute a single variable: deviant bebaviour $(\alpha=.94 ; M=.88 ; S D=.77)$, with higher scores reflecting a greater involvement in deviant conduct.

School Failure of the participants was measured by the number of years failed in school. In the Portuguese school system, the failure of a school year occurs in one of the following situations: (1) when students fail more than two courses, or (2) when students fail both Portuguese and Mathematics. Information about school failure of the participants was collected based on the following questions: 'Have you ever failed a year at school?', and 'If your answer was yes, how many times did you fail?' Nearly half of the participants (44\%) had never failed a school year. It is important to highlight the fact that from the $56 \%$ of the participants that had already failed a year at school, $68 \%$ were attending vocational schools. Indeed, when we compare the success and failure rates of participants attending regular schools and vocational schools, we encounter enormous differences. Of those who attend regular schools, $66 \%$ had never failed and 
Table 2. Pearson correlations between variables

\begin{tabular}{|c|c|c|c|c|c|c|}
\hline & & I & 2 & 3 & 4 & 5 \\
\hline I & Procedural justice & I & & & & \\
\hline 2 & Distributive justice & $.59^{* *}$ & I & & & \\
\hline 3 & Institutional authorities & $.42^{* *}$ & $.35^{* *}$ & I & & \\
\hline 4 & Deviant behaviour & $-.28^{* *}$ & $-.2 I^{* *}$ & $-.39^{* *}$ & 1 & \\
\hline \multirow[t]{3}{*}{5} & School failure & $.16 * *$ & .10 & $-.11^{*}$ & $.35^{* *}$ & 1 \\
\hline & Means & 3.41 & 3.56 & 3.03 & .88 & 1.27 \\
\hline & Standard deviations & .71 & .79 & .49 & .77 & 1.26 \\
\hline
\end{tabular}

Note. ${ }^{*} p<.05 ;{ }^{* *} p<.01$.

the remaining $34 \%$ had already failed at least once. However, in vocational schools, only $5 \%$ of the participants had never failed whilst $95 \%$ had already failed at least once. These differences are owed, in part, to the fact that the students with a history of failure in regular education, but who are still within the period of compulsory education, are frequently led into vocational schools. In these schools, teaching has a strong component of practice and is, above all, directed towards the development of professional knowledge and competency, with the view to integrating the students into the workplace.

\section{Procedure}

Several schools within the urban area of Lisbon were contacted. Since we were interested in having an equivalent number of students with school success and with school failure, both regular schools and vocational schools were contacted. After receiving the authorization of the school principals for the collection of student data, class teachers indicated in which classroom period the questionnaires could be administered and they also distributed the parent-consent forms. With the agreement of all the school principals, a passive consent procedure was chosen: parents were asked to sign and return the consent forms only if they did not wish their child to participate in the study. Participants were informed that the questionnaire was anonymous, their answers would remain completely confidential, they could ask any question about the study after completing the questionnaire, and their participation was voluntary. All measures were administered on the same day in the exclusive presence of the researcher. Participants took approximately $30 \mathrm{~min}$ to complete the questionnaire.

\section{Results}

\section{Correlations between variables}

Pearson correlation analyses among all variables were carried out (see Table 2). As expected, results indicated a significant negative relationship between the justice judgements about teachers and the deviant behaviour of adolescents. There was also a significant positive relationship between the justice judgments and the EIA. DJ was not significantly associated with school failure, while PJ showed a significant positive association with school failure. The EIA was also significantly and negatively related with school failure and with deviance and, finally, deviant behaviour was significantly and positively related with school failure. 


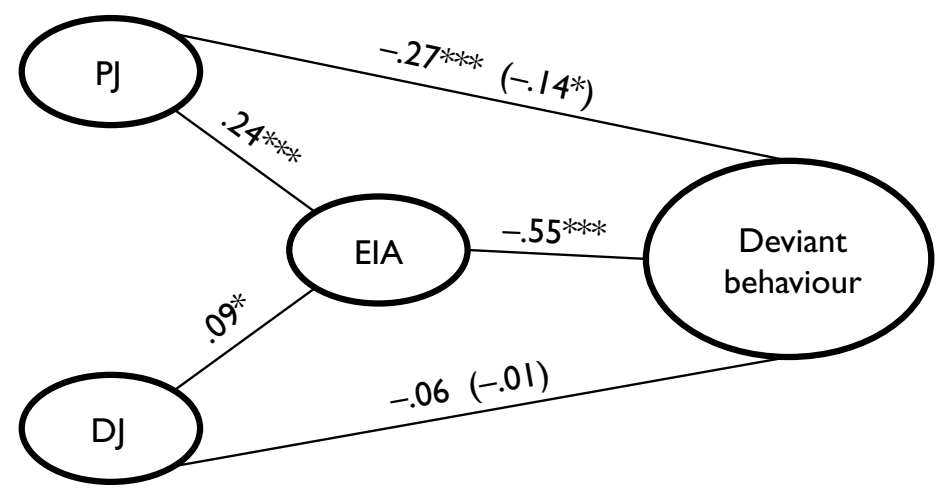

Figure I. Mediation analyses of the association between the justice judgments and deviant behaviour Note. Path values represent unstandardized regression coefficients from bootstrapping analyses. Values in parentheses represent the direct effects of independent variables (PJ and DJ) on deviant behaviour after including the mediator (EIA). ${ }^{*} p<.05,{ }^{* *} p<.01$, ${ }^{* * *} p<.001$.

\section{Mediation analyses}

To test the mediation effect of the EIA on the relationship between justice judgments about teachers and adolescent deviant behaviour, bootstrap analyses were conducted using methods described by Preacher and Hayes (2008). Although, the causal steps methodology proposed by Baron and Kenny (1986) and the product-of-coefficients methodology developed by Sobel $(1982,1986)$ are the most often used in the literature for testing mediation hypotheses, bootstrapping has some advantages over both: (1) it does not rely on the assumption of a normal sampling distribution, and (2) it is a method that simultaneously increases power while maintaining reasonable control over the Type I error rate (Preacher \& Hayes, 2004, 2008). Bootstrapping is a non-parametric resampling technique that empirically generates an approximation of the sampling distribution. This method provides point estimates and percentile bootstrap confidence intervals (CI) for total and indirect effects.

In the present study, the bootstrap analyses were conducted using the SPSS macro created by Preacher and Hayes (see Preacher \& Hayes, 2008) for bootstrap analyses with multiple mediators ${ }^{1}$. CI were based on 5,000 bootstrap samples and were improved using bias correction and acceleration (BCa) as the authors suggest. CI containing zero are interpreted as being not significant. Two models were estimated: the first testing the ability of the EIA to mediate the effects of PJ on deviance, and the second testing the ability of EIA to mediate the effects of DJ on deviance. However, since we were interested in determining the unique ability of each of the justice dimensions (PJ and DJ) to account for variation in adolescent deviant behaviour, DJ entered as a covariate in the first model, and PJ entered as a covariate in the second model. The results of both models are presented in Figure 1.

Starting with PJ, the bootstrap results indicated that the total effect of PJ on deviant behaviour (total effect of PJ $=-.27, p<.00001$ ) decreased when the EIA was included in the model (direct effect of PJ $=-.14, p<.05$ ). Results also showed that the total indirect effect (i.e., the difference between total and direct effects) of PJ on deviant

'Although we had a single mediator model, we used the SPSS macro for bootstrap analyses with multiple mediators, since it is the only one available that allows the inclusion of covariates. 


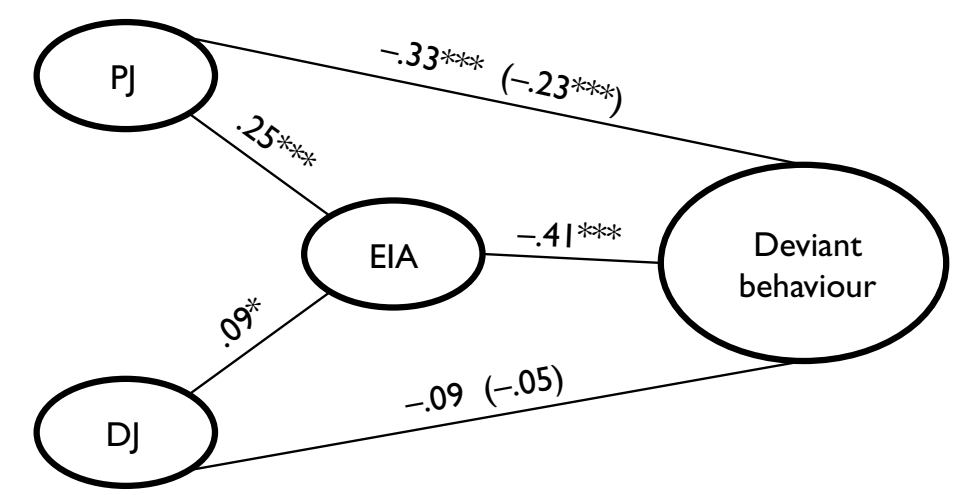

Figure 2. Mediation analyses of the association between the justice judgments and deviant behaviour, when controlling school failure.

Note. Path values represent unstandardized regression coefficients from bootstrapping analyses, with school failure as a covariate. Values in parentheses represent the direct effects of independent variables (PJ and DJ) on deviant behaviour after including the mediator (EIA). ${ }^{*} p<.05,{ }^{* *} p<.01,{ }^{* * *} p<.001$.

behaviour through the mediator was significant, with a point estimate of -.1317 and $95 \%$ BCa CI of $-.2065,-.0645$. These results indicate that the association between perceptions about the PJ of teachers and the involvement of adolescents in deviant behaviour is partially mediated by the EIA.

A different pattern of results was, however, found for DJ. The bootstrap results indicated that the total effect of DJ on deviant behaviour was not significant in the first place (total effect of $\mathrm{DJ}=-.06, p=.3304$ ) and, therefore, there was no possible mediation effect in this case. It was, nonetheless, possible to test for the indirect effect of DJ on deviance through the EIA. Indeed, the bootstrap results indicated that the effect of DJ decreased when the EIA was included in the model (direct effect of DJ $=-.01$, $p=.8155$ ) and that the total indirect effect of DJ on deviant behaviour through the EIA was significant, with a point estimate of -.0472 and $95 \%$ BCa CI of $-.1023,-.0064$. In other words, these results seem to indicate that although there is no significant direct association between DJ and deviance, DJ is indirectly associated with deviant behaviour through its association with the EIA.

Given that the literature shows a strong association between adolescent school failure and their involvement in deviant behaviour, one of our aims was to ensure that the mediation effects hypothesized were not explained by a third cause, such as school failure. Therefore, we repeated the bootstrap analysis, but this time adding school failure also as a covariate in each model. Results are presented in Figure 2.

Overall, adding school failure to our model did not change the pattern of results previously obtained, but it increased our model's ability to account for variation in adolescent deviant behaviour $\left(R^{2}\right.$ of the previous model $=.18, p<.00001 ; R^{2}$ of the current model $=.32, p<.00001)$. Again, the bootstrap results showed that the total effect of PJ on deviant behaviour (total effect of PJ $=-.33, p<.00001$ ) decreased when the mediator (EIA) was included in the model (direct effect of PJ $=-.23$, $p<.001$ ). Also, the total indirect effect of PJ on deviant behaviour through the mediator was significant, with a point estimate of -.1044 and $95 \%$ BCa CI of $-.1685,-.0541$, again indicating a significant partial mediation. Once more, although the bootstrap results for DJ showed that the total effect of DJ on deviant behaviour was not significant (total 
effect of DJ $=-.09, p=.1149)$, this effect decreased when the EIA was included in the model (direct effect of DJ $=-.05, p=.3566$ ) and the total indirect effect of DJ on deviant behaviour through the EIA was significant, with a point estimate of -.0393 and $95 \% \mathrm{BCa}$ CI of $-.0861,-.0080$. This again indicates that DJ judgments about teachers are only indirectly associated with the involvement of adolescents in deviant conducts through their association with the evaluation of other institutional authorities. To sum up, the results obtained when controlling for adolescent school failure strengthen our hypothesis by showing that the mediation effect proposed remained significant over and above the effect of school failure on deviant behaviour (partial effect of school failure = $.23, p<.00001)$.

\section{Discussion}

Although the two theoretical approaches underpinning our hypotheses (the RMA, as well as Emler \& Reicher's theory on delinquency) seem to share some arguments, research attempting to associate them is almost non-existent. To our knowledge, the only exception to this was the study carried out by Gouveia-Pereira et al. (2003), which showed that positive justice judgments about teachers promote the internalization of positive representations about other authorities outside school. Therefore, our main goal was to extend these results further and contribute to the articulation between these two theoretical approaches.

As predicted, we found justice perceptions about teachers to be negatively associated with adolescent deviant behaviour. These results confirmed our first hypothesis and seem to indicate that the more adolescents feel that they are fairly treated by school authorities; the less they engage in deviant conduct. A different pattern of results was, however, found for PJ and for DJ. Although Pearson correlations revealed that DJ was negatively associated with the occurrence of deviant behaviour, when this association was analysed with PJ as a covariate, DJ was no longer significant. This suggests that the association between distributive judgments and deviant behaviour was spurious and was due to the strong association between judgments about DJ and PJ.

These differences between the effects of procedural and DJ were not surprising. According to the RMA, people are much more concerned with the justice of the procedures used and with the quality of the interpersonal treatment received than with the justice of the results obtained. However, besides giving support to the hypothesis of the RMA, our results have also the merit of extending them by showing that the fairness of authorities is not only positively associated with positive behaviour, such as the legitimacy of authorities or the adoption of pro-social behaviour (e.g., GouveiaPereira et al., 2003; Lind et al., 1997; Sousa \& Vala, 2002; Sunshine \& Tyler, 2003; Tyler, 1990, 1997; Tyler \& Caine, 1981; Tyler \& Huo, 2002; Tyler et al., 1996; Tyler \& Wakslak, 2004), but it is also negatively related with negative behaviour, such as the involvement in deviant conduct.

Our results also enlarge previous findings that associate some school-related variables with adolescent aggressive behaviour in the school context (Estévez et al., 2005; López et al., 2008; Murray \& Murray, 2004; Ochoa et al., 2007). We found that the judgment of adolescents about their teachers' justice was related not only with aggressive behaviour, but also with their involvement in other deviant conduct. And further, these justice judgments were related with conduct occurring not only at school, but also outside school, which seems to indicate that the experiences of (in)justice are critical in the explanation of adolescent deviant behaviour. One could, however, question why these experiences 
of (in)justice with authorities at school are related to the behaviour that adolescents have in other contexts. This association is not obvious at first sight. Following Emler and Reicher's $(1995,2005)$ argument, we have hypothesized that one of the reasons explaining this association was that adolescents' representations about authorities in the school setting are generalized to other institutional authorities of society, such as police officers, judges, or the law, which, in turn, are closely associated with deviance. The results of the bootstrap analysis confirmed this second hypothesis by showing that the EIA was a significant mediator in the relationship between the PJ of teachers and the deviant behaviour of adolescents. This suggests that the more adolescents perceive their teachers as using fair procedures and treating them respectfully, the more they positively evaluate other institutional authorities, such as the police, the court, or the law. In turn, the more positive the evaluation of those institutional authorities is, the less often adolescents report having engaged in deviant behaviour.

Moreover, the mediation effects hypothesized remained significant after controlling for school failure, which reinforces the robustness of the model proposed. But, if adding school failure to the mediation analysis did not change the pattern of results previously obtained, it almost doubled our model's ability to account for variation in adolescent deviant behaviour. Indeed, the strong association between school failure and delinquency is one of the best documented findings in the literature (see, e.g., Hargreaves, 1967; Kelly, 1975; Reiss \& Rhodes, 1961; West \& Farrington, 1977) and for that reason we think that it is absolutely necessary to take it into account when analysing the relationship between school-related variables and deviance. There were, however, two curious aspects about our results. The first one is that judgments about DJ were not significantly related with school failure. This suggests that those adolescents who have never failed at school and those who have already failed at least 1 year do not have different perceptions of the fairness of the grades they received. The second one is that given the strong association between school failure and deviance, we might expect that adolescent evaluations about the justice or the favourability of the grades received (distributive judgments) would also be associated with deviance, which was not the case. Indeed, the bootstrap analysis showed that judgments about teachers' DJ were only indirectly associated with the involvement of adolescents' in deviant conduct, through their association with the EIA. Therefore, teachers' DJ seems to affect adolescents' evaluation of other institutional authorities of society (even if it does so in a lesser degree than teachers' PJ), but it does not directly affect the involvement of adolescents in deviance, contrary to what occurs with PJ.

Those aspects about the justice of teachers that seem to determine adolescents' evaluations of institutional authorities and their involvement in deviance are whether teachers treat them with respect and dignity, whether they use neutral and impartial procedures in decision making and behave the same with everyone, and whether teachers are honest and show concern for their needs and rights. According to the justice models, these aspects are so important because the use of fair procedures and the quality of the interpersonal treatment received communicate to adolescents that they are valued members in that group, which provides positive identity information (Lind \& Tyler, 1988; Tyler \& Blader, 2003; Tyler \& Lind, 1992; Tyler et al., 1996). Besides this, fair procedures and the quality of interpersonal treatment are certainly important in promoting a sense that authorities are trustworthy, which, according to Emler and Reicher (2005), will prevent adolescents from feeling excluded and alienated from the protection of authorities, and consequently from involvement in delinquency. 
When we proposed to analyse the associations between justice judgments about teachers, the EIA and the involvement in deviant conduct, our starting point was that this process had its origins at school. The justice and injustice situations experienced with school authorities would constitute a model or a reference from which adolescents would make inferences about what to expect from other formal authorities of society, which are governed by the same principles and rules. However, this is not the only possible interpretation for our results. It is equally possible to think that adolescent' evaluations of institutional authorities will influence their judgments about the fairness of teachers, and that, in turn, will affect their involvement in deviance. It could even be that it is adolescent involvement in deviant conduct that leads to a negative reaction from legal authorities and this reaction, in turn, will affect the judgment about the justice of authorities. We, in fact, conducted a correlational study with a cross-sectional design and relationships between independent, mediator, and dependent variables may not necessarily be causal (Holmbeck, 1997). Therefore, we must be extremely cautious when making causal inferences based on the data available. Only experimental and longitudinal studies could confirm the causal link of this process. Nonetheless, given that in the developmental trajectory of any child experiences with school authorities are certainly prior to their experiences with other formal authorities, and prior to their involvement in deviant activities, the first interpretation is the one that seems more plausible to us.

Future research might contribute to enrich our understanding of the associations between the relationship of adolescents with authorities and their deviant behaviour by identifying other possible mediators in this process. For instance, to what extent might the justice judgements on school authorities also be related to deviant behaviour through their impact on adolescent identity? It would also be interesting to analyse whether there are interaction effects between variables, namely between the fairness of teachers and the EIA, or between the fairness of teachers and school failure. Another important issue to address in future research is the identification of other variables that might contribute to a better understanding of the associations found. For instance, research within the field of the Belief in a Just World (BJW) has analysed the association between BJW and some school-related variables, namely teachers' fairness (Correia \& Dalbert, 2007; Dalbert, 2004; Dalbert \& Maes, 2002). It has also analysed the association between BJW and the rule-compliant behaviour of young prisoners, or the intentions of young adults at risk to engage in delinquent activities (Otto \& Dalbert, 2005; Sutton \& Winnard, 2007). Therefore, it would be interesting to take the effect of BJW into account when analysing the relationship between justice perceptions about authorities and adolescents involvement in deviance.

To conclude, the aims of the current research were reached. The results obtained provided preliminary empirical support for the articulation between the RMA proposed by Tyler and Lind (1992) and the theory of juvenile delinquency proposed by Emler and Reicher $(1995,2005)$. These results might be considered a first step in the process of understanding the relationship between justice judgments about authorities and the involvement of adolescents in deviant conduct. Therefore, although there is still a lot to be explored and clarified before we fully understand this relationship, we think that these preliminary findings are an important contribution in this direction.

\section{Acknowledgements}

C. Sanches was supported by a PhD grant from the FCT - Foundation for Science and Technology (SFRH/BD/40174/2007). 


\section{References}

Adams, J. S. (1965). Inequity in social exchange. In L. Berkowitz (Ed.), Advances in experimental social psychology (Vol. 2, pp. 267-299). New York: Academic Press.

Baron, R., \& Kenny, D. (1986). The moderator-mediator variable distinction in social psychological research: Conceptual, strategic, and statistical considerations. Journal of Personality and Social Psychology, 51(6), 1173-1182. doi:10.1037/0022-3514.51.6.1173

Berkowitz, L., \& Walster, E. (1976). Equity theory: Toward a general theory of social interaction. In L. Berkowitz \& E. Walster (Eds.), Advances in experimental social psychology (Vol. 9). New York: Academic Press.

Blankemeyer, M., Flannery, D., \& Vazsonyi, A. (2002). The role of aggression and social competence in children's perceptions of the child-teacher relationship. Psychology in the Schools, 39(3), 293-304. doi:10.1002/pits. 10008

Brockner, J., \& Wiesenfeld, B. (1996). An integrative framework for explaining reactions to decisions: Interactive effects of outcomes and procedures. Psychological Bulletin, 120(2), 189-208. doi:10.1037/0033-2909.120.2.189

Correia, I., \& Dalbert, C. (2007). Belief in a just world, justice concerns, and well-being at Portuguese schools. European Journal of Psychology of Education, 22(4), 421-437. doi:10.1007/BF03173464

Dalbert, C. (2004). The implications and functions of just and unjust experiences in school. In C. Dalbert \& H. Sallay (Eds.), The justice motive in adolescence and young adulthood: Origins and consequences (pp. 117-134). London: Routledge.

Dalbert, C., \& Maes, J. (2002). Belief in a just world as a personal resource in school. In M. Ross \& D. T. Miller (Eds.), The justice motive in everyday life (pp. 365-381). New York: Cambridge University Press. doi:10.1017/CBO9780511499975.020

Emler, N. (1992). Childhood origins of beliefs about institutional authority. In H. Haste \& J. TorneyPurta (Eds.), The development of political understanding: A new perspective (pp. 65-77). San Francisco: Jossey-Bass.

Emler, N., Ohana, J., \& Moscovici, S. (1987). Children's beliefs about institutional roles: A cross-national study of representations of the teacher's role. British Journal of Educational Psychology, 57(1), 26-37. doi:10.1111/j.2044-8279.1987.tb03058.x

Emler, N., \& Reicher, S. (1987). Orientations to institutional authority in adolescence. Journal of Moral Education, 16(2), 108-116. doi:10.1080/0305724870160203

Emler, N., \& Reicher, S. (1995). Adolescence and delinquency-The collective management of reputation. Oxford: Blackwell.

Emler, N., \& Reicher, S. (2005). Delinquency: Cause or consequence of social exclusion?. In D. Abrams, M. A. Hogg, \& J. M. Marques (Eds.), The social psychology of inclusion and exclusion (pp. 211-241). New York: Psychology Press.

Estévez, E., Musitu, G., \& Herrero, J. (2005). The influence of violent behavior and victimization at school on psychological distress: The role of parents and teachers. Adolescence, 40(157), 183-195.

Folger, R. (1996). Distributive and procedural justice: Multifaceted meanings and interrelations. Social Justice Research, 9, 395-416. doi:10.1007/BF02196992

Gouveia-Pereira, M. (2008). Percepções de justiça na adolescência: A escola e a legitimação das autoridades institucionais [Justice perceptions in adolescence: The school and the legitimacy of institutional authorities]. Lisboa: Fundação Calouste Gulbenkian /Fundação para a Ciência e a Tecnologia.

Gouveia-Pereira, M., \& Carita, A. (2005). Percepções de justiça em contexto escolar e familiar e sua relação com o exercício da cidadania e com comportamentos desviantes [ustice perceptions in school and family settings and their relationship with citizenship and with deviant behaviour]. Unpublished manuscript, ISPA University, Lisbon.

Gouveia-Pereira, M., \& Pires, S. (1999). Experiência escolar e julgamentos acerca da autoridade [School experience and judgments about authority]. Análise Psicológica, 17(1), 97-110. 
Gouveia-Pereira, M., Vala, J., Palmonari, A., \& Rubini, M. (2003). School experience, relational justice and legitimation of institutional authorities. European Journal of Psychology of Education, 18(3), 309-325. doi:10.1007/BF03173251

Hargreaves, D. H. (1967). Social relations in a secondary school. London: Routledge.

Hirschi, T. (1969). Causes of delinquency. Berkeley: University of California Press.

Hoge, R., Andrews, D., \& Leschied, A. (1996). An investigation of risk and protective factors in a sample of youthful offenders. Journal of Child Psychology and Psychiatry, 37(4), 419-424. doi:10.1111/j.1469-7610.1996.tb01422.x

Holmbeck, G. (1997). Toward terminological, conceptual, and statistical clarity in the study of mediators and moderators: Examples from the child-clinical and pediatric psychology literatures. Journal of Consulting and Clinical Psychology, 65(4), 599-610. doi:10.1037/0022006X.65.4.599

Kelly, D. (1975). Status origins, track position, and delinquent involvement: A self-report analysis. The Sociological Quarterly, 16(2), 264-271. doi:10.1111/j.1533-8525.1975.tb00944.x

Leventhal, G. S. (1980). What should be done with equity theory? New approaches to the study of fairness in social relationships. In K. J. Gergen, M. S. Greenberg, \& R. H. Willis (Eds.), Social exchange: Advances in theory and research (pp. 27-55). New York: Plenum.

Levy, K. (2001). The relationship between adolescent attitudes toward authority, self-concept, and delinquency. Adolescence, 36(142), 333-346.

Lind, E., \& Tyler, T. (1988). The social psychology of procedural justice. New York: Plenum Press.

Lind, E., Tyler, T., \& Huo, Y. (1997). Procedural context and culture: Variation in the antecedents of procedural justice judgments. Journal of Personality and Social Psychology, 73(4), 767-780. doi: $10.1037 / 0022-3514.73 .4 .767$

Loeber, R. (1996). Developmental continuity, change, and pathways in male juvenile problem behaviors and delinquency. In J. D. Hawkins (Ed.), Delinquency and crime: Current theories (pp. 1-27). New York: Cambridge University Press.

López, E., Pérez, S., Ochoa, G., \& Ruiz, D. (2008). Adolescent aggression: Effects of gender and family and school environments. Journal of Adolescence, 31(4), 433-450. doi:10.1016/j.adolescence.2007.09.007

Murray, C., \& Murray, K. (2004). Child level correlates of teacher-student relationships: An examination of demographic characteristics, academic orientations, and behavioral orientations. Psychology in the Schools, 41(7), 751-762. doi:10.1002/pits.20015

Ochoa, G., Lopez, E., \& Emler, N. (2007). Adjustment problems in the family and school contexts, attitude towards authority, and violent behavior at school in adolescence. Adolescence, 42(168), 779-794.

Otto, K., \& Dalbert, C. (2005). Belief in a just world and its functions for young prisoners. Journal of Research in Personality, 39(6), 559-573. doi:10.1016/j.jrp.2005.01.004

Palmonari, A., \& Rubini, M. (1998). Adolescenti, scuola e rapporto con le autorità istituzionali. [Adolescents, school and the relationship with institutional authority]. In F. P. Colluci (Ed.), Il cambiamento imperfetto. I citadini, le comunicazione politica, I leader nell'Italia degli anni novanta [The imperfect change. The citizens, the political communication, the leaders in Italy during the nineties] (pp. 209-217). Milan, Edizione Unicopli.

Palmonari, A., Rubini, M., \& Casoni, E. (1999). A psycho-social approach to the study of the orientation toward formal authority. Paper presented at the XII General Meeting of the EAESP. Oxford (6-11 July).

Preacher, K., \& Hayes, A. (2004). SPSS and SAS procedures for estimating indirect effects in simple mediation models. Behavior Research Methods, Instruments \& Computers, 36(4), 717-731. doi: $10.3758 / \mathrm{BF} 03206553$

Preacher, K., \& Hayes, A. (2008). Asymptotic and resampling strategies for assessing and comparing indirect effects in multiple mediator models. Behavior Research Methods, 40(3), 879-891. doi:10.3758/BRM.40.3.879

Reicher, S., \& Emler, N. (1985). Delinquent behaviour and attitudes to formal authority. British Journal of Social Psychology, 24(3), 161-168. doi:10.1111/j.2044-8309.1985.tb00677.x 
Reinke, W., \& Herman, K. (2002). Creating school environments that deter antisocial behaviors in youth. Psychology in the Schools, 39(5), 549-560. doi:10.1002/pits.10048

Reiss, A., \& Rhodes, A. (1961). The distribution of juvenile delinquency in the social class structure. American Sociological Review, 26, 720-732. doi:10.2307/2090201

Rigby, K., \& Rump, E. (1979). The generality of attitude to authority. Human Relations, 32, 469-487. doi:10.1177/001872677903200603

Rigby, K., \& Rump, E. (1981). Attitudes toward parents and institutional authorities during adolescence. Journal of Psychology: Interdisciplinary and Applied, 109(1), 109-118.

Rigby, K., Schofield, P., \& Slee, P. (1987). The similarity of attitudes towards personal and impersonal types of authority among adolescent school children. Journal of Adolescence, 10(3), 241-253. doi:10.1016/S0140-1971(87)80002-7

Smith, D., \& McVie, S. (2003). Theory and method in the Edinburgh study of youth transitions and crime. British Journal of Criminology, 43(1), 169-195. doi:10.1093/bjc/43.1.169

Sobel, M. E. (1982). Asymptotic confidence intervals for indirect effects in structural equations models. In S. Leinhart (Ed.), Sociological methodology 1982 (pp. 290-312). San Francisco: Jossey-Bass.

Sobel, M. E. (1986). Some new results on indirect effects and their standard errors in covariance structure models. In N. Tuma (Ed.), Sociological methodology 1986 (pp. 159-186). Washington, DC: American Sociological Association.

Sousa, F., \& Vala, J. (2002). Relational justice in organizations: The group-value model and support for change. Social Justice Research, 15(2), 99-121. doi:10.1023/A:1019967705790

Sunshine, J., \& Tyler, T. (2003). The role of procedural justice and legitimacy in shaping public support for policing. Law \& Society Review, 37(3), 513-548. doi:10.1111/1540-5893.3703002

Sutton, R., \& Winnard, E. (2007). Looking ahead through lenses of justice: The relevance of justworld beliefs to intentions and confidence in the future. British Journal of Social Psychology, 46(3), 649-666. doi:10.1348/014466606 × 166220

Tajfel, H., \& Turner, J. (1986) The social identity theory of intergroup behaviour. In S. Worchel \& L. W. Austin (Eds.), Psychology of intergroup relations (pp. 7-24). Chicago: Nelson Hall.

Tarry, H., \& Emler, N. (2007). Attitude, values and moral reasoning as predictors of delinquency. British Journal of Developmental Psychology, 25(2), 169-183. doi:10.1348/026151006 × 113671

Turner, J., Hogg, M., Oakes, P., Reicher, S., \& Wetherell, M. (1987). Rediscovering the social group: A self-categorization theory. Cambridge: Basil Blackwell.

Tyler, T. (1990). Why people obey the law. New Haven: Yale University Press.

Tyler, T. (1997). The psychology of legitimacy: A relational perspective on voluntary deference to authorities. Personality and Social Psychology Review, 1(4), 323-345. doi:10.1207/s15327957pspr0104_4

Tyler, T., \& Blader, S. (2000). Cooperation in groups: Procedural justice, social identity, and behavioral engagement. New York: Psychology Press.

Tyler, T., \& Blader, S. (2003). The group engagement model: Procedural justice, social identity, and cooperative behavior. Personality and Social Psychology Review, 7(4), 349-361. doi:10.1207/S15327957PSPR0704_07

Tyler, T., \& Caine, A. (1981). The influence of outcomes and procedures on satisfaction with formal leaders. Journal of Personality and Social Psychology, 41(4), 642-655. doi:10.1037/00223514.41.4.642

Tyler, T., Degoey, P., \& Smith, H. (1996). Understanding why the justice of group procedures matters: A test of the psychological dynamics of the group-value model. Journal of Personality and Social Psychology, 70(5), 913-930. doi:10.1037/0022-3514.70.5.913

Tyler, T., \& Huo, Y. (2002). Trust in the law: Encouraging public cooperation with the police and courts. New York: Russell Sage Foundation.

Tyler, T., \& Lind, E. (1992). A relational model of authority in groups. Advances in experimental social psychology (Vol. 25, pp. 115-191). San Diego: Academic Press. doi:10.1016/S00652601(08)60283-X 
Tyler, T. R., \& Smith, H. (1997). Social justice and social movements. In D. Gilbert, S. Fiske, \& G. Lindzey (Eds.), Handbook of social psychology (pp. 595-629). New York: McGraw-Hill.

Tyler, T. R., \& Wakslak, C. J. (2004), Profiling and police legitimacy: Procedural justice, attributions of motive, and acceptance of police authority. Criminology, 42(2): 253-282. doi: 10.1111/j.1745-9125.2004.tb00520.x

Van den Bos, K., \& Lind, E. (2001). The psychology of own versus others' treatment: Selforiented and other-oriented effects on perceptions of procedural justice. Personality and Social Psychology Bulletin, 27(10), 1324-1333. doi:10.1177/01461672012710008

Vazsonyi, A., Pickering, L., Junger, M., \& Hessing, D. (2001). An empirical test of a general theory of crime: A four-nation comparative study of self-control and the prediction of deviance. Journal of Research in Crime and Delinquency, 38(2), 91-131. doi:10.1177/0022427801038002001

Vermunt, R., Van der Kloot, W., \& Van der Meer, J. (1993). The effect of procedural and interactional criteria on procedural fairness judgements. Social Justice Research, 6(2), 183194. doi:10.1007/BF01048476

West, D., \& Farrington, D. (1977). The delinquent way of life: Third report of the Cambridge study in delinquent development. Oxford: Heinemann Educational Books.

Received 2 I February 2010; revised version received I 4 June 201 I 